\title{
Induction of Long-Term Memory by Exposure to Novelty Requires Protein Synthesis: Evidence for a Behavioral Tagging
}

\author{
Diego Moncada ${ }^{1}$ and Haydée Viola ${ }^{1,2}$ \\ ${ }^{1}$ Instituto de Biología Celular y Neurociencias, Facultad de Medicina, and ²Departamento de Fisiología, Biología Molecular y Celular, Facultad de Ciencias \\ Exactas y Naturales, Universidad de Buenos Aires, 1121 Buenos Aires, Argentina
}

\begin{abstract}
A behavioral analog of the synaptic tagging and capture process, a key property of synaptic plasticity, has been predicted recently. Here, we demonstrate that weak inhibitory avoidance training, which induces short- but not long-term memory (LTM), can be consolidated into LTM by an exploration to a novel, but not a familiar, environment occurring close in time to the training session. This memorypromoting effect caused by novelty depends on activation of dopamine $D_{1} / D_{5}$ receptors and requires newly synthesized proteins in the dorsal hippocampus. Thus, our results indicate the existence of a behavioral tagging process in which the exploration to a novel environment provides the plasticity-related proteins to stabilize the inhibitory avoidance memory trace.
\end{abstract}

Key words: inhibitory avoidance; spatial novelty; behavioral tag; hippocampus; long-term memory; rats

\section{Introduction}

Long-term potentiation (LTP) is a phenomenon thought to reflect a cellular mechanism involved in learning and memory formation. The properties of LTP concerning its long duration, input specificity, and associative characteristics support its wide use as a model for the investigation of a basic memory mechanism (Martin et al., 2000; Reymann and Frey, 2007).

It was demonstrated recently that hippocampal early-LTP can be behaviorally reinforced into late-LTP by exposing rats to a novel environment (Li et al., 2003; Straube et al., 2003a; Davis et al., 2004). This effect was observed after a short period following novelty and was absent in rats exposed to a familiar environment. Therefore, it was postulated that plasticity-related proteins (PRPs), synthesized under the influence of novelty, could transform transient forms of plasticity into long-lasting ones. In that sense, novelty-induced LTP reinforcement was blocked when a protein synthesis inhibitor was applied before exploration onset (Straube et al., 2003b). To explain how the synthesized proteins interact with specific inputs, the synaptic tagging hypothesis was postulated in which the PRPs are captured at specific synapses that were previously tagged by synaptic activity (Frey and Morris, 1997, 1998a,b). A synaptic tag transiently marks a synapse after activation in a way that allows the local recognition of newly

Received Nov. 10, 2006; revised May 23, 2007; accepted May 30, 2007.

This work was supported by grants from Universidad de Buenos Aires Ciencia y Tecnica, Agencia Nacional de Promocion Cientifica y Tecnologica, and the Antorchas Foundation. We thank Dr. Jorge H. Medina, Pedro Bekinschtein, and Maria C. Martinez for helpful comments and the discussion of this manuscript.

Correspondence should be addressed to Dr. Haydée Viola, Instituto de Biología Celulary Neurociencias, Paraguay 21553 piso, Facultad de Medicina, Universidad de Buenos Aires, 1121 Buenos Aires, Argentina. E-mail: hviola@fmed.uba.ar.

D0I:10.1523/JNEUROSCI.1083-07.2007

Copyright $\odot 2007$ Society for Neuroscience $\quad$ 0270-6474/07/2774476-06\$15.00/0 synthesized proteins to produce an enduring change in transmission efficiency (Martin and Kosik, 2002).

The main goal of this work is to study whether a process of synaptic tagging and protein capture operates during the formation of long-term memory (LTM). Therefore, we asked whether it is feasible to induce LTM for training (inhibitory avoidance task) that ordinarily produces only short-term forms of memory (STM), if this training occurs close to another behavioral event (open-field exploration) that provides the PRPs necessary for establishment of LTM.

Given that the hippocampal region is an essential component of the circuit that detects and responds to new stimuli (Knight, 1996; Grunwald et al., 1998; Moncada and Viola, 2006) and that its pharmacological or surgical manipulation impairs memory formation of the inhibitory avoidance learning task (Bernabeu et al.,1997; Taubenfeld et al., 2001; Martinez et al., 2002), the effects of the interaction between the spatial novel exploration and the inhibitory avoidance training in the rat hippocampus is a suitable behavioral design to evaluate the behavioral tagging hypothesis.

\section{Materials and Methods}

Subjects. Male Wistar rats (age, 2 months; weight, 180-210 g) from our own breeding colony were used. The animals were housed five to a cage, with water and food ad libitum, under a $12 \mathrm{~h}$ light/dark cycle (lights on at 7:00 A.M.) at a constant temperature of $23^{\circ} \mathrm{C}$. All behavioral testing was conducted during the light phase of the cycle.

The experimental protocols for this study followed the guidelines of the National Institutes of Health Guide for the Care and Use of Laboratory Animals and were approved by the Animal Care and Use Committee of the University of Buenos Aires.

Drug. Anisomycin and $R-(+)-7$ chloro-8-hydroxy-3-methyl-1phenyl-2,3,4,5-tetrahydro-1 $H$-3-benzazepine hydrochloride (SCH23390) were purchased from Sigma (St. Louis, MO). Eighty micrograms of anisomycin were infused in a volume of $0.8 \mu \mathrm{l}$ per side. Anisomycin was dissolved 
in $\mathrm{HCl}$, diluted in saline, and adjusted to $\mathrm{pH} 7.4$ with $\mathrm{NaOH}$ (Vianna et al., 2000). SCH23390 was dissolved in saline, and $2 \mu \mathrm{g}$ in a volume of $0.8 \mu \mathrm{l}$ per side was infused. We found this concentration of dopamine $D_{1} / D_{5}$ receptor antagonist effective and devoid of hypokinetic effects.

Surgery and drug infusion. For cannula implantation, rats were deeply anesthetized ( $70 \mathrm{mg} / \mathrm{kg}$ ketamine and $8 \mathrm{mg} / \mathrm{kg}$ xylazine), and 22 gauge cannulas were stereotaxically aimed $1.0 \mathrm{~mm}$ above the pyramidal cell layer of the CA1 region of the dorsal hippocampus at coordinates -4.2 $\mathrm{mm}$ anterior, $\pm 3.0 \mathrm{~mm}$ lateral, and $1.4 \mathrm{~mm}$ ventral, from the atlas of Paxinos and Watson (1986). Animals were allowed to recover from surgery for $4 \mathrm{~d}$ before the experimental procedures. To infuse the drug, a 30 gauge cannula with its tip protruding $1.0 \mathrm{~mm}$ beyond that of the guide was used. The infusion cannulas were linked by an acrylic tube to a microsyringe, and infusions were performed over $1 \mathrm{~min}$; the cannulas were left in place for 1 additional minute to minimize backflow. Histological examination of cannula placements was performed. After the end of the behavioral procedures, $1 \mu \mathrm{l}$ of $4 \%$ methylene-blue solution was infused into the implanted site. Animals were killed by decapitation 15 min later, and the brains were stored in formalin for histological localization of the infusion sites. Only data from animals with correct cannula implants (95\% of the rats) were included in statistical analyses.

Behavioral apparatus and behavioral procedures. The open-field apparatus is a $50-\mathrm{cm}$-high, $50-\mathrm{cm}$-wide, and $39-\mathrm{cm}$-deep arena with black plywood walls and a brown floor divided into nine squares by black lines. A novel environment exploration consists of a 5 min open-field session. When it was desirable to familiarize the animals with the arena, a $30 \mathrm{~min}$ open-field session was performed $1 \mathrm{~d}$ before of the experiment (Moncada and Viola, 2006).

The inhibitory avoidance apparatus is a $50 \times 25 \times 25 \mathrm{~cm}$ Plexiglas box with a 5 -cm-high, 8 -cm-wide, and 25 -cm-long platform on the left end of a series of bronze bars, which constituted the floor of the box. In the training session, rats were placed on the platform facing the left rear corner of the box. When they stepped down, putting their four paws on the bronze bars, they received a weak footshock $(0.15 \mathrm{~mA}, 2 \mathrm{~s})$ or a strong footshock $(0.5 \mathrm{~mA}, 3 \mathrm{~s})$. After this, the animals returned to their home cage. The animals were submitted to a test session to measure STM ( 15 or 60 min after training) or LTM (24 h after training). Memory was measured by comparing the step-down latency in the training session to that in the test session.

Behavioral protocols. To avoid unnecessary emotional stress, all rats were previously handled daily for $3 \mathrm{~min}$ for $3 \mathrm{~d}$. Within each cage, rats were randomly assigned to the control group or to a different experimental group.

In Figure $1 a$, different groups of rats received a weak inhibitory avoidance training session and were submitted to a test session $15 \mathrm{~min}, 60 \mathrm{~min}$, or $24 \mathrm{~h}$ later.

In Figure $1 b$, different groups of rats received a weak inhibitory avoidance training session and received a 5 min open-field session several times $(120,60,30 \mathrm{~min})$ before. Control animals were not submitted to open-field exploratory session. The inhibitory avoidance test session was performed at $24 \mathrm{~h}$.

In Figure $2 a$, different groups of rats explored the open-field box for 5 min for the first time or for the second time ( $24 \mathrm{~h}$ after a $30 \mathrm{~min}$ openfield session). One hour later, they received weak inhibitory avoidance training, and LTM was tested at $24 \mathrm{~h}$. Control animals were handled but were not submitted to the open-field exploratory session.

To assess shock sensitivity, animals were placed in the grid of the inhibitory avoidance box without a platform. After $30 \mathrm{~s}$ of free exploration, they received $0.1,0.15,0.2,0.25,0.3,0.4,0.5$, and $0.6 \mathrm{~mA}, 1.0 \mathrm{~s}$, footshocks in successive trials separated by $15 \mathrm{~s}$. Vocalizations and jumping thresholds expressed in milliamperes were recorded for each animal during the procedure (Depino et al., 2004). The shock sensitivity test was performed 30,60, or $120 \mathrm{~min}$ after a $5 \mathrm{~min}$ novel open-field exposure or in control animals (not exposed to the open field).

In Figure $2 b$, rats received a strong inhibitory avoidance training session $1 \mathrm{~h}$ after a $5 \mathrm{~min}$ open-field exploratory session or handling procedure. Twenty-four hours later, the animals were submitted to a test session.

In Figure $2 d$, cannulated rats were infused into the dorsal hippocam- pus with vehicle or SCH23390, 13 min before exposure to a novel open field. One hour later, they received weak inhibitory avoidance training, and $24 \mathrm{~h}$ later, the animals were submitted to a test session. Control animals were infused with vehicle but not submitted to the open field.

In Figure $3 a$, cannulated rats were submitted to a 5 min open-field session, and immediately after, they received a bilateral infusion of vehicle or anisomycin into the CA1 region of the dorsal hippocampus. Control animals were infused with vehicle but not submitted to the openfield session. The inhibitory avoidance test session was performed at $24 \mathrm{~h}$.

In Figure $3 b$, cannulated rats were submitted to strong inhibitory avoidance training $13 \mathrm{~min}$ after the infusion of vehicle or anisomycin and tested $24 \mathrm{~h}$ later. A third group of rats explored a novel open field, received the bilateral infusion of anisomycin $47 \mathrm{~min}$ later, and were submitted to strong inhibitory avoidance training $13 \mathrm{~min}$ later. The test session was performed $24 \mathrm{~h}$ later.

In Figure $4 a$, different groups of rats were trained in weak inhibitory avoidance and several times $(0,15,60$, and $120 \mathrm{~min})$ after were exposed to a $5 \mathrm{~min}$ open-field session. Control animals were not submitted to the open field. The inhibitory avoidance test session was performed at $24 \mathrm{~h}$.

In Figure $4 b$, we analyzed the effect of anisomycin infusion immediately after the $5 \mathrm{~min}$ open-field session delivered $15 \mathrm{~min}$ after the inhibitory avoidance training. The test session was performed $24 \mathrm{~h}$ later

Data analysis. The Newman-Keuls multiple comparison test after one-way ANOVA was applied for the statistical analysis of behavioral data, using the Prism 4 software (GraphPad Software San Diego, CA).

\section{Results}

Previous exposure to an open field promotes LTM formation of the inhibitory avoidance task (inhibitory avoidance-LTM) during a restricted time window

We submitted rats to an inhibitory avoidance training, a hippocampus-dependent learning task that was shown to induce LTP in the CA1 region (Whitlock et al., 2006), and tested whether LTM formation was induced by exposing animals to a novel environment. In the inhibitory avoidance training session, rats were gently placed on the platform; as they stepped down onto the grid, they received a weak footshock $(0.15 \mathrm{~mA}, 2 \mathrm{~s})$. During the test session, memory was assessed as the time the animal spent in the platform before stepping down. This weak training did not induce LTM tested $24 \mathrm{~h}$ later but did induce a transient STM evidenced $15 \mathrm{~min}$ but not $60 \mathrm{~min}$ after training (Fig. 1a) $(p<$ $0.001)$.

To examine the effect of spatial novelty on the formation of inhibitory avoidance LTM, we submitted rats to a 5-min-long open-field session at several times before inhibitory avoidance training. Open-field exploration $1 \mathrm{~h}$ before weak inhibitory avoidance training, but not $2 \mathrm{~h}$ or $30 \mathrm{~min}$ before, induced the formation of LTM (Fig. 1b) ( $p<0.001)$. We found no differences in sensitivity to shock between experimental and control groups when the analysis was performed 120,60, and 30 min after open-field exploration (vocalization thresholds: control, $0.237 \pm$ $0.013 ;-120 \mathrm{~min}, 0.241 \pm 0.019 ;-60 \mathrm{~min}, 0.263 \pm 0.021 ;-30$ min, $0.236 \pm 0.015$; jumping thresholds: control, $0.445 \pm 0.034$; $-120 \mathrm{~min}, 0.422 \pm 0.031 ;-60 \mathrm{~min}, 0.411 \pm 0.026$; $-30 \mathrm{~min}$, $0.393 \pm 0.028 ; p>0.05$, Newman-Keuls analysis after one-way ANOVA). Thus, there is a permissive action of spatial novelty on inhibitory avoidance memory formation, which is restricted to a critical time window and is not attributable to changes in shock sensitivity.

\section{Novelty but not familiar environment exploration promotes inhibitory avoidance-LTM}

To directly address whether the LTM induction was caused by the novel nature of the environment, a group of animals was familiarized with the novel environment by allowing exploration for a 
a

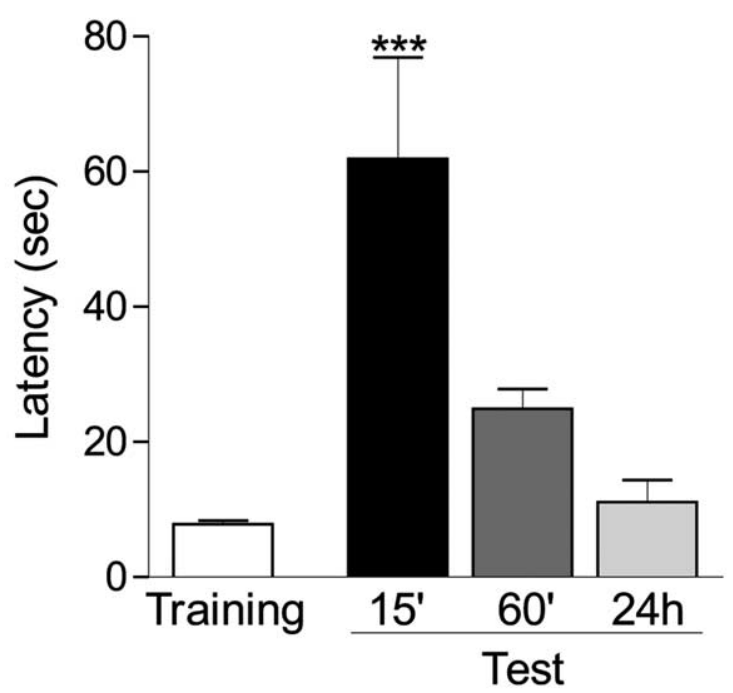

b

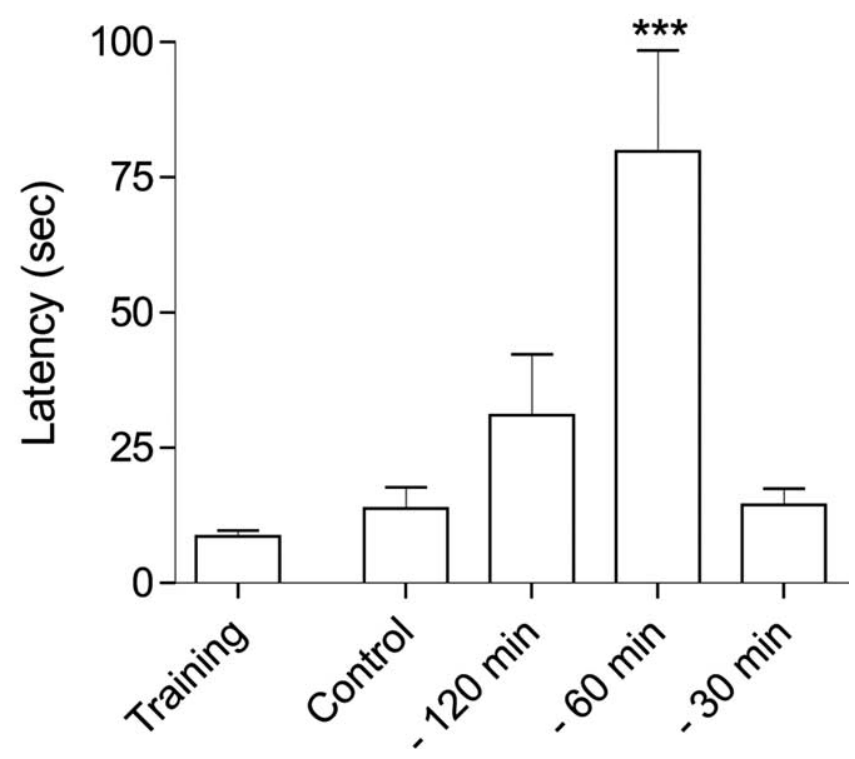

Figure 1. Exploration to an open field induces inhibitory avoidance-LTM formation. Rats were trained in a step-down inhibitory avoidance task with a weak footshock $(0.15 \mathrm{~mA}, 2 \mathrm{~s})$. Step-down latency is expressed as mean \pm SEM. $\boldsymbol{a}$, Different groups of rats were tested to evaluate STM (15 or 60 min after training) and LTM (24h after training). ${ }^{* * *} p<0.001$ versus all groups (Newman-Keuls analysis after one-way ANOVA; $n=10-15$ ). $\boldsymbol{b}$, LTM was tested $24 \mathrm{~h}$ after training rats in the absence (control) or in the presence of open-field exposure given at several times before the training session $(-120,-60$, or $-30 \mathrm{~min}) .{ }^{* *} p<0.001$ versus all groups (Newman-Keuls analysis after one-way ANOVA; $n=10-15$ ).

30 min period on the previous day (Moncada and Viola, 2006). Inhibitory avoidance-LTM was not observed when rats explored, for $5 \mathrm{~min}$, the now-familiar open field $1 \mathrm{~h}$ before inhibitory avoidance training (Fig. $2 a)(p>0.05)$. These experiments show that the novel aspect of the unfamiliar environment is crucial for the induction of inhibitory avoidance-LTM formation.

To answer whether novelty can also modulate an established LTM, we trained rats using a strong footshock stimulus capable of inducing inhibitory avoidance-LTM $(0.4 \mathrm{~mA}, 2 \mathrm{~s} ; p<0.05)$ (Fig. $2 b$ ). We observed that animals exposed to the novel open field $1 \mathrm{~h}$ before this inhibitory avoidance training did not show improved
LTM retention (Fig. 2b). Our results resemble those in which a brief novelty pre-exposure positively modulates LTP induced by weak high-frequency stimulation (Li et al., 2003; Straube et al., 2003a) but not LTP induced by strong high-frequency stimulation (Xu et al., 1998).

Several works suggest that novelty affects hippocampal plasticity in a dopamine-dependent manner (Li et al., 2003; Kentros et al., 2004). Moreover, it was recently shown that dopamine is released within the hippocampus from the ventral tegmental area to process novelty signal (Lisman and Grace, 2005). Therefore, we investigated whether the induction of inhibitory avoidanceLTM by previous exploration of a novel open field was prevented by infusion of $\mathrm{D}_{1} / \mathrm{D}_{5}$ receptor antagonist into the CA1 region of the dorsal hippocampus (Fig. $2 c$ ). As shown in Figure $2 d$, the administration of SCH23390 ( $2 \mu$ g per side), 13 min before the exposure to the open field, impaired LTM retention for the inhibitory avoidance task.

In a separate experiment, we found that the same dose of SCH23390 (2 $\mu$ g per side) was able to block novelty detection, when infused $13 \mathrm{~min}$ before novel open-field exploration. Both vehicle and SCH23390 groups actively explored the open field during the first session. In contrast, when rats were allowed to explore it for a second time $3 \mathrm{~h}$ later, vehicle-infused animals but not the SCH23390-infused animals showed significant habituation [number of crossings; $81.80 \pm 5.96$ vs $41.60 \pm 4.75(p<$ $0.001 ; n=9)$ and $92.33 \pm 6.03$ vs $79.50 \pm 7.64(p>0.05 ; n=7)$, respectively; paired $t$ test].

Together, these experiments demonstrate that hippocampal administration of SCH23390, which blocks the novelty detection process, prevents inhibitory avoidance-LTM induction by the novel open-field exploration. Therefore, the effect of novelty on inhibitory avoidance-LTM induction is mediated by dopamine $\mathrm{D}_{1} / \mathrm{D}_{5}$ receptor activation in the hippocampal CA1 region.

\section{Novelty-induced LTM formation is dependent on protein synthesis}

It was proposed that new PRPs synthesized by behavioral manipulations could reinforce early-LTP by mechanisms of synaptic tagging (Straube et al., 2003b; Reymann and Frey, 2007). Extending to behavioral memory, the existence of a behavioral analog of synaptic tagging was predicted but not yet proved (Martin et al., 2000; Morris, 2006). Therefore, a behavioral tagging process would implicate that protein synthesis induced by one behavioral task is used to stabilize a transient form of memory (STM) of another learning task into long-lasting ones (LTM) (Morris, 2006). Thus, is open-field exploration providing the proteins necessary to consolidate an inhibitory avoidance-LTM of training that only induces STM? To test this hypothesis, we infused the protein synthesis inhibitor anisomycin into the CA1 region of the dorsal hippocampus immediately after the open-field exploration session, $1 \mathrm{~h}$ before weak inhibitory avoidance training. We found that inhibition of protein synthesis prevented the promoting effect of novelty on LTM formation after weak inhibitory avoidance training (Fig. $3 a$, left) $(p<0.01)$. On the other hand, anisomycin infusion $1 \mathrm{~h}$ before strong inhibitory avoidance training did not modify LTM retention, indicating that anisomycin did not impair acquisition or consolidation of LTM (Fig. $3 a$, right). In contrast, immediate pretraining administration of anisomycin hinders LTM for this task (Igaz et al., 2002; Cammarota et al., 2003; Bekinschtein et al., 2007).

Having established that novelty-induced inhibitory avoidance-LTM is dependent on new protein synthesis (Fig. 3a, left) that provides PRPs required to promote LTM, we next deter- 

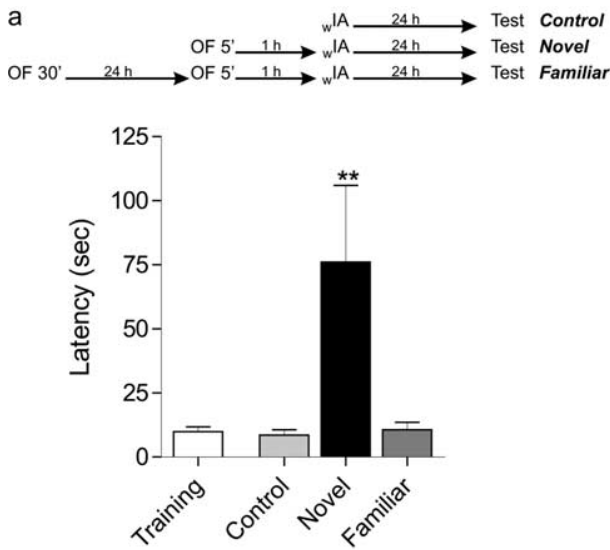

C

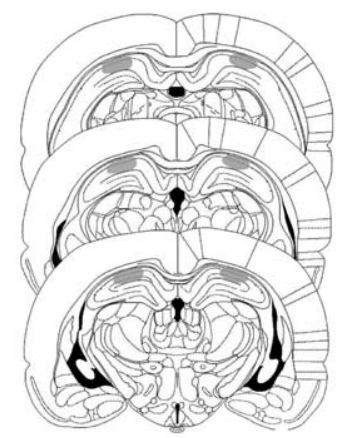

b
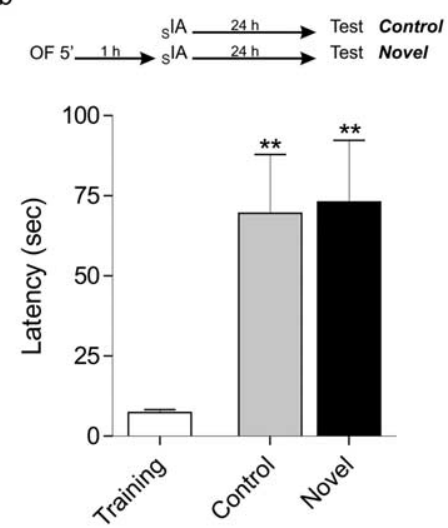

d

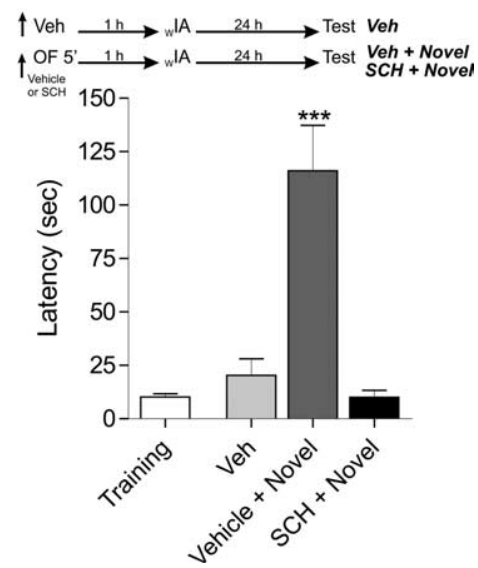

Figure 2. Hippocampal inhibition of dopamine $D_{1} / D_{5}$ receptors prevents inhibitory avoidance-LTM formation induced specifically by exposure to novelty. Rats were trained in a step-down inhibitory avoidance task using either a weak $(0.15 \mathrm{~mA}, 2 \mathrm{~s} ; \mathrm{w}$ IA) or strong $(0.4 \mathrm{~mA}, 2 \mathrm{~s} ; \mathrm{s}$ A) footshock. Step-down latency is expressed as mean \pm SEM. $\boldsymbol{a}$, Flow chart of the experimental protocol using a ${ }_{w}$ IA. LTM was tested $24 \mathrm{~h}$ after training rats in the absence (control) or in the presence of a novel or a familiar open-field exposure $1 \mathrm{~h}$ before the inhibitory avoidance training session. ${ }^{* *} p<0.01$ versus all groups (Newman-Keuls analysis after one-way ANOVA; $n=8)$. $\boldsymbol{b}$, Flow chart of the experimental protocol using an ${ }_{\mathrm{s}}$ IA. LTM was tested $24 \mathrm{~h}$ after training rats in the absence (control) or in the presence of a novel open-field exposure (novel) $1 \mathrm{~h}$ before the inhibitory avoidance training session. ${ }^{* *} p<0.01$ versus training (Newman-Keuls analysis after one-way ANOVA; $n=14$ ). $c$, Schematic representation of rat brain sections showing the extension of the area (gray) reached by the infusions in the CA1 region of the dorsal hippocampus. $\boldsymbol{d}$, Flow chart of the experimental protocol using $\mathrm{a}_{w}$ IA. LTM was tested $24 \mathrm{~h}$ after training rats in the absence (Veh) or in the presence of a novel open-field exposure. Rats were infused with either vehicle (Vehicle + Novel) or SCH23390 (SCH + Novel) 13 min before exposure to a novel open field and were trained in ${ }_{w} I A 1 \mathrm{~h}$ later. ${ }^{* * *} p<0.001$ versus all groups (Newman-Keuls analysis after one-way ANOVA; $n=10)$. OF, Open field.

mined whether novelty could rescue the amnesia induced by the infusion of anisomycin $13 \mathrm{~min}$ before strong inhibitory avoidance training. Confirming previous findings (Igaz et al., 2002; Cammarota et al., 2003; Bekinschtein et al., 2007), the infusion of anisomycin 13 min before training totally blocked LTM when tested $24 \mathrm{~h}$ after training (Fig. $3 b$ ). Previous exposure of rats to an open-field session rescued the amnesic effect of anisomycin (Fig. $3 b)(p<$ 0.05 ), inducing LTM with similar retention scores to those observed in Figure $3 a$ (left). Therefore, protein synthesis elicited by exposure to a novel open field is necessary to promote the transformation of STM into LTM and prevents the amnesic effect of anisomycin on the formation of LTM.

\section{Posttraining open-field exposure also promotes inhibitory avoidance-LTM during a restricted time window}

The symmetry of the synaptic tag hypothesis predicts that the order of the synaptic tag setting and newly synthesized proteins may be unimportant (Frey and Morris, 1998a), as long as these two events coincide during a time window. Thus, we examined the effect of posttraining exposure to spatial novelty after weak inhibitory avoidance training. We submitted rats to a 5-min-long open-field session at several times after inhibitory avoidance training. Open-field exploration $15 \mathrm{~min}$ after the training induced LTM (Fig. 4a) $(p<$ $0.001)$. Again, this effect was protein synthesis dependent because anisomycin infused into the CA1 region immediately after the open-field exploration hindered the promoting effect of novelty on LTM formation (Fig. 4b). A moderate effect was also observed on memory expression at $24 \mathrm{~h}$ in animals exposed to the open field $1 \mathrm{~h}$ after inhibitory avoidance training (Fig. 4a) $(p<0.05)$. The exposure to novelty immediately or $2 \mathrm{~h}$ after the inhibitory avoidance training failed to promote LTM. Thus, this permissive action of the exploration to a novel open field, after weak inhibitory avoidance training, over LTM induction is also restricted to a critical time window.

\section{Discussion}

It was recently found that spatial novelty facilitates the induction and persistence of LTP in the CA1 region and in the dentate gyrus of the hippocampal formation ( $\mathrm{Li}$ et al., 2003; Straube et al., 2003a,b; Davis et al., 2004). Given that LTP is considered a physiological cellular model of learning and memory formation (Martin et al., 2000; Sacchetti et al., 2002; Gruart et al., 2006; Morris, 2006) and that one-trial inhibitory avoidance training was shown to induce LTP in CA1 in vivo (Whitlock et al., 2006), we used this task to test the prediction that a behavioral analog of the synaptic tagging and capture hypothesis, a key property of synaptic plasticity, occurs in vivo.

The main finding of our study is that protein synthesis products generated by a novel experience promote the storage of new information acquired during another learning task. This is based on four series of data. First, the exploration to a novel environment promoted inhibitory avoidance-LTM formation. Given that a brief exposure to a novel environment does not modify anxiety levels, locomotor and exploratory activities one $1 \mathrm{~h}$ later (Izquierdo et al., 2003), or shock sensitivity, novelty-induced inhibitory avoidance-LTM formation is not attributable to a nonspecific influence of the novel environment exploration on performance during inhibitory avoidance training. Second, this promoting effect was observed during a critical time window and was absent in animals that explored a familiar environment. The window of efficacy relies on the temporal coincidence of the tag (determined by its time course of decay) and the availability of PRPs to be captured (dependent of the velocity of its synthesis and its halflife). In that sense, the absence of a facilitatory effect of novelty exposure at $30 \mathrm{~min}$ before or immediately after inhibitory avoidance training could be attributable to the interference or resetting 
of the tag generated by the inhibitory avoidance training. Consistent with this assumption, it has been recently demonstrated that a short theta frequency stimulation, resembling the rhythm of activity observed in hippocampal neurons when rats explore a novel environment, given close to the induction of LTP, negatively affected the setting of the tag (Sajikumar and Frey, 2004; Young and Nguyen, 2005; Young et al., 2006). For instance, a lowfrequency stimulation maintains its inhibitory effect on late-LTP for 20-40 min after its application, and the authors propose that this phenomenon occurs by inhibiting synaptic tagging through its action on the protein kinase A pathway (Young et al., 2006). Future experiments will be performed to study the possibility that exposure to a novel open field $30 \mathrm{~min}$ before the inhibitory avoidance training could inhibit the setting of the tag through this mechanism. Third, the induction of inhibitory avoidance-LTM formation by spatial novelty was blocked by delivering the protein synthesis inhibitor anisomycin into the CA1 region immediately after the exposure to a novel environment. Frey and colleagues (Straube et al., 2003b; Uzakov et al., 2005) have previously found that novelty- and holeboard training-induced LTP reinforcement in the hippocampus, is dependent on new protein synthesis. Indeed, we demonstrated that the amnesia induced by blockade of protein synthesis immediately before strong inhibitory avoidance training was rescued by a previous exposure to novelty. This result supports that spatial novelty provides PRPs, which could be hijacked by the synaptic tag because of the strong inhibitory avoidance training performed in the presence of anisomycin. Thus, our findings resemble those described by Frey and Morris (1997) in their seminal work.

Finally, we demonstrated that the exposure to a novel open field $15 \mathrm{~min}$ and $1 \mathrm{~h}$ after the inhibitory avoidance training also promoted LTM formation for this task. This is consistent with the idea of symmetry of the synaptic tagging hypothesis, in which the setting of the tag and the synthesis of the PRPs could occur in indistinguishable order (Frey and Morris, 1998a). This fact makes it less probable that the plasticity factors must be present in the synaptic terminals before learning occurs, which would lower the threshold for induction of LTM.

To characterize the neurotransmitter systems involved in the induction of inhibitory avoidance-LTM by a novel environment exploration, we decided to study the participation of the dopaminergic inputs to the hippocampus, which are known to be activated by novelty detection processes (Lisman and Grace, 2005). Our results demonstrated that local hippocampal blockade of dopamine $D_{1} / D_{5}$ receptors, before the exposure to a novel

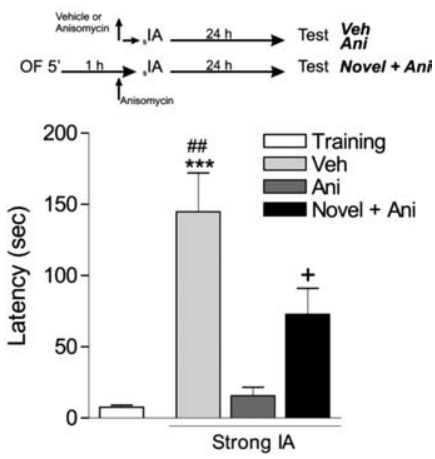

Figure 3. Inhibition of protein synthesis prevents inhibitory avoidance-LTM formation induced by exposure to novelty. $\boldsymbol{a}$, Flow chart of the experimental protocol. Rats received bilateral intra-CA1 infusions of vehicle (Novel + Veh) or anisomycin (Novel + Ani), immediately after a novel open field, and were submitted to either a weak $(0.15 \mathrm{~mA}, 2 \mathrm{~s})$ or a strong $(0.4 \mathrm{~mA}, 2 \mathrm{~s})$ inhibitory avoidance training session $1 \mathrm{~h}$ later. Notice that we adjusted the parameters of footshock in the right panel to obtain LTM retention scores similar to those shown in the left panel, where novelty promoted LTM after a weak training protocol. Control rats received vehicle $1 \mathrm{~h}$ before inhibitory avoidance training but were not exposed to the open field (Veh). Latencies were measured $24 \mathrm{~h}$ after inhibitory avoidance training. ${ }^{* *} p<0.01$ versus all weak inhibitory avoidance training groups $(n=16)$ ${ }^{+} p<0.05$ versus training $(n=7)$; Newman-Keuls analysis after one-way ANOVA. $\boldsymbol{b}$, Flow chart of the experimental protocol. Animals were submitted to a strong inhibitory avoidance training session ( $\mathrm{s} A)$ and received bilateral intrahippocampal infusions to a novel open field $1 \mathrm{~h}$ before ${ }_{s} \mathrm{~A}$ (Novel + Ani). ${ }^{* *} p<0.001$ versus training and Ani-infused group; ${ }^{* \#} p<0.01$ versus Novel + Ani; ${ }^{+} p<0.05$ versus training and Ani; Newman-Keuls analysis after one-way ANOVA $(n=7-10) .0$ F, Open field; IA,

a

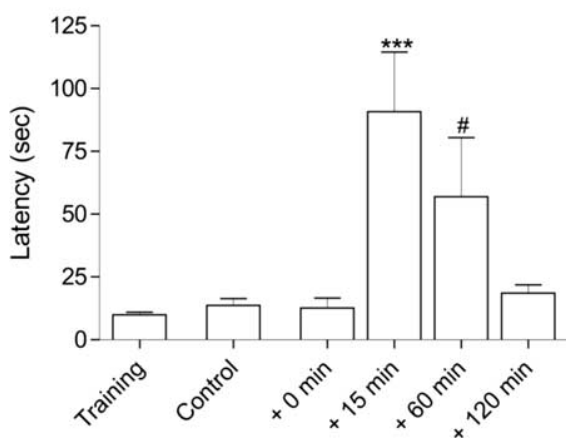

Figure 4. Open-field exploration after weak inhibitory avoidance training also induces inhibitory avoidance-LTM in a timedependant manner. $\boldsymbol{a}$, Different groups of animals were submitted to a weak inhibitory avoidance training session $(0.15 \mathrm{~mA}, 2 \mathrm{~s})$ and exposed to a novel open field at several times $(+0,+15,+60$, or $+120 \mathrm{~min})$. Inhibitory avoidance-LTM was tested $24 \mathrm{~h}$ after training. ${ }^{* * *} p<0.001$ versus training, control, $+0 \mathrm{~min}$, and $+120 \mathrm{~min}$; ${ }^{\#} p<0.05$ versus all groups, Newman-Keuls (Novel + Ani) immediately after a novel open-field (OF) exposure performed 15 min after a weak inhibitory avoidance training session $\left({ }_{w} \mid A\right)$ training $(0.15 \mathrm{~mA}, 2 \mathrm{~s})$. Control animals were infused but not exposed to the open field (Veh). Latencies were measured $24 \mathrm{~h}$ after inhibitory avoidance training. ${ }^{* *} p<0.001$ versus all groups (Newman-Keuls analysis after one-way ANOVA; $n=8$ ).

environment, prevents the novelty-induced inhibitory avoidance-LTM. Given that the late phase of LTP is strongly regulated by dopaminergic inputs to the hippocampus (Frey et al. 1990, 1991; Li et al., 2003; Huang and Kandel, 2006), that the $\mathrm{D}_{1} / \mathrm{D}_{5}$ receptor activation stimulates local protein synthesis in the dendrites of hippocampal neurons (Smith et al., 2005), and our present findings (Figs. $2 d, 3 a$, left), it could be possible that $\mathrm{D}_{1} / \mathrm{D}_{5}$ receptor activation may trigger local synthesis of PRPs necessary to transform STM into LTM. In this context, it has been recently postulated that dopaminergic release on hippocampal neurons participates in synaptic integration that makes local translational activation feasible (Govindarajan et al., 2006). There is also a 
possibility that dopamine/glutamate interaction is required to trigger PRP synthesis providing some synergistic signal, leading to local or somatic mRNA translation, or gene activation $\left(\mathrm{O}^{\prime} \mathrm{Car}-\right.$ roll and Morris, 2004). Therefore, the dopaminergic influence on novelty-induced LTP (Li et al., 2003) and novelty-induced LTM (the present findings) gives further support to the synaptic tag and capture hypothesis. Additional studies surely will be needed to elucidate the identity of the PRPs and the underlying mechanisms involved in the promoting effect of novelty on inhibitory avoidance-LTM formation.

In conclusion, our findings provide the first evidence for a behavioral tagging process during which a training experience that only promotes STM is able to induce LTM if the triggering event (inhibitory avoidance training) occurs close to another one (spatial novelty) that provides the PRPs required for stabilization of the memory trace. Also, we demonstrated that this behavioral tagging process depends on the functionality of dopamine $D_{1} / D_{5}$ receptors and translational machinery, both acting in the dorsal hippocampus at the time of novelty intervention.

\section{References}

Bekinschtein P, Cammarota M, Igaz LM, Bevilaqua LR, Izquierdo I, Medina JH (2007) Persistence of long-term memory storage requires a late protein synthesis- and BDNF-dependent phase in the hippocampus. Neuron 53:261-277.

Bernabeu R, Bevilaqua L, Ardenghi P, Bromberg E, Schmitz P, Bianchin M, Izquierdo I, Medina JH (1997) Involvement of hippocampal cAMP/ cAMP-dependent protein kinase signaling pathways in a late memory consolidation phase of aversively motivated learning in rats. Proc Natl Acad Sci USA 94:7041-7046.

Cammarota M, Bevilaqua LR, Kerr D, Medina JH, Izquierdo I (2003) Inhibition of mRNA and protein synthesis in the CAl region of the dorsal hippocampus blocks reinstallment of an extinguished conditioned fear response. J Neurosci 23:737-741.

Davis CD, Jones FL, Derrick BE (2004) Novel environments enhance the induction and maintenance of long-term potentiation in the dentate gyrus. J Neurosci 24:6497-6506.

Depino AM, Alonso M, Ferrari C, del Rey A, Anthony D, Besedovsky H, Medina JH, Pitossi F (2004) Learning modulation by endogenous hippocampal IL-1: blockade of endogenous IL-1 facilitates memory formation. Hippocampus 14:526-535.

Frey U, Morris RG (1997) Synaptic tagging and long-term potentiation. Nature 385:533-536.

Frey U, Morris RG (1998a) Weak before strong: dissociating synaptic tagging and plasticity-factor accounts of late-LTP. Neuropharmacology 37:545-552.

Frey U, Morris RG (1998b) Synaptic tagging: implications for late maintenance of hippocampal long-term potentiation. Trends Neurosci 21:181-188.

Frey U, Schroeder H, Matthies H (1990) Dopaminergic antagonists prevent long-term maintenance of posttetanic LTP in the CA1 region of rat hippocampal slices. Brain Res 522:69-75.

Frey U, Matthies H, Reymann KG, Matthies H (1991) The effect of dopaminergic D1 receptor blockade during tetanization on the expression of long-term potentiation in the rat CAl region in vitro. Neurosci Lett 129:111-114.

Govindarajan A, Kelleher RJ, Tonegawa S (2006) A clustered plasticity model of long-term memory engrams. Nat Rev Neurosci 7:575-583.

Gruart A, Munoz MD, Delgado-Garcia JM (2006) Involvement of the CA3CA1 synapse in the acquisition of associative learning in behaving mice. J Neurosci 26:1077-1087.

Grunwald T, Lehnertz K, Heinze HJ, Helmstaedter C, Elger CE (1998) Verbal novelty detection within the human hippocampus proper. Proc Natl Acad Sci USA 95:3193-3197.

Huang YY, Kandel ER (2006) Age-related enhancement of a protein synthesis-dependent late phase of LTP induced by low frequency pairedpulse stimulation in hippocampus. Learn Mem 13:298-306.

Igaz LM, Vianna MR, Medina JH, Izquierdo I (2002) Two time periods of hippocampal mRNA synthesis are required for memory consolidation of fear-motivated learning. J Neurosci 22:6781-6789.
Izquierdo LA, Barros DM, Medina JH, Izquierdo I (2003) Exposure to novelty enhances retrieval of very remote memory in rats. Neurobiol Learn Mem 79:51-56.

Kentros CG, Agnihotri NT, Streater S, Hawkins RD, Kandel ER (2004) Increased attention to spatial context increases both place field stability and spatial memory. Neuron 42:283-295.

Knight R (1996) Contribution of human hippocampal region to novelty detection. Nature 383:256-259.

Li S, Cullen WK, Anwyl R, Rowan MJ (2003) Dopamine-dependent facilitation of LTP induction in hippocampal CA1 by exposure to spatial novelty. Nat Neurosci 6:526-531.

Lisman JE, Grace AA (2005) The hippocampal-VTA loop: controlling the entry of information into long-term memory. Neuron 46:703-713.

Martin KC, Kosik KS (2002) Synaptic tagging-who's it? Nat Rev Neurosci 3:813-820.

Martin SJ, Grimwood PD, Morris RG (2000) Synaptic plasticity and memory: an evaluation of the hypothesis. Annu Rev Neurosci 23:649-711.

Martinez I, Quirarte GL, Diaz-Cintra S, Quiroz C, Prado-Alcala RA (2002) Effects of lesions of hippocampal fields CA1 and CA3 on acquisition of inhibitory avoidance. Neuropsychobiology 46:97-103.

Moncada D, Viola H (2006) Phosphorylation state of CREB in the rat hippocampus: a molecular switch between spatial novelty and spatial familiarity? Neurobiol Learn Mem 86:9-18.

Morris RG (2006) Elements of a neurobiological theory of hippocampal function: the role of synaptic plasticity, synaptic tagging and schemas. Eur J Neurosci 23:2829-2846.

O'Carroll CM, Morris RG (2004) Heterosynaptic co-activation of glutamatergic and dopaminergic afferents is required to induce persistent longterm potentiation. Neuropharmacology 47:324-332.

Paxinos G, Watson C (1986) The rat brain in stereotaxic coordinates, Ed 2. San Diego: Academic.

Reymann KG, Frey JU (2007) The late maintenance of hippocampal LTP: requirements, phases, "synaptic tagging," "late-associativity" and implications. Neuropharmacology 52:24-40.

Sacchetti B, Lorenzini CA, Baldi E, Bucherelli C, Roberto M, Tassoni G, Brunelli M (2002) Time-dependent inhibition of hippocampal LTP in vitro following contextual fear conditioning in the rat. Eur J Neurosci 15:143-150.

Sajikumar S, Frey JU (2004) Resetting of "synaptic tags" is time- and activity-dependent in rat hippocampal CAl in vitro. Neuroscience 129:503-507.

Smith WB, Starck SR, Roberts RW, Schuman EM (2005) Dopaminergic stimulation of local protein synthesis enhances surface expression of GluR1 and synaptic transmission in hippocampal neurons. Neuron 45:765-779.

Straube T, Korz V, Frey JU (2003a) Bidirectional modulation of long-term potentiation by novelty-exploration in rat dentate gyrus. Neurosci Lett 344:5-8.

Straube T, Korz V, Balschun D, Frey JU (2003b) Requirement of betaadrenergic receptor activation and protein synthesis for LTP-reinforcement by novelty in rat dentate gyrus. J Physiol (Lond) 552:953-960.

Taubenfeld SM, Wiig KA, Monti B, Dolan B, Pollonini G, Alberini CM (2001) Fornix-dependent induction of hippocampal CCAAT enhancerbinding protein $\beta$ and $\delta$ co-localizes with phosphorylated cAMP response element-binding protein and accompanies long-term memory consolidation. J Neurosci 21:84-91.

Uzakov S, Frey JU, Korz V (2005) Reinforcement of rat hippocampal LTP by holeboard training. Learn Mem 12:165-171.

Vianna MR, Alonso M, Viola H, Quevedo J, de Paris F, Furman M, de Stein ML, Medina JH, Izquierdo I (2000) Role of hippocampal signaling pathways in long-term memory formation of a nonassociative learning task in the rat. Learn Mem 7:333-340.

Whitlock JR, Heynen AJ, Shuler MG, Bear MF (2006) Learning induces long-term potentiation in the hippocampus. Science 313:1093-1097.

Xu L, Anwyl R, Rowan MJ (1998) Spatial exploration induces a persistent reversal of long-term potentiation in rat hippocampus. Nature 394:891-894.

Young JZ, Nguyen PV (2005) Homosynaptic and heterosynaptic inhibition of synaptic tagging and capture of long-term potentiation by previous synaptic activity. J Neurosci 25:7221-7231.

Young JZ, Isiegas C, Abel T, Nguyen PV (2006) Metaplasticity of the latephase of long-term potentiation: a critical role for protein kinase A in synaptic tagging. Eur J Neurosci 23:1784-1794. 